\title{
Magisterio de la Iglesia y poder político en la Sevilla de la Restauración (1881-1890)
}

JOSE LEONARDO RUIZ SANCHEZ

La aprobación en España a finales de la pasada centuria de una ley que ampliaba hasta lo universal el sufragio, supuso un hito en el paso desde postulados liberales a tesis democráticas. Desde el punto de vista legal nada impedía que el gobierno de unos pocos fuera a partir de entonces representativo de todos los ciudadanos. A esta alturas, los estudios realizados sobre el comportamiento electoral de los partidos políticos españoles dúrante la Restauración nos dan justa medida de lo que significó en puridad la implantación de dicho sufragio: los principios legales habían quedado establecidos, pero, en la práctica, dejaban sentir en exceso el lastre liberal; lastre que sólo podía menguarse mediante normativas legales complementarias a la ley y, sobre todo, de una apuesta en firme de los propios partidos liberales del turno.

Coetáneo a este proceso se produjo en el seno de la Iglesia una progresiva adaptación a la realidad política vigente desde los inicios de la revolución liberal. De trataba de superar aquellos antagonismo que habían tenido su punto culminante durante el mandato de Pío IX. Su sucesor León XIII (1878-1903), cuyo pontificado discurre a lo largo de toda la primera fase de la Restauración, procuró conciliar la Iglesia con las nuevas formas de poder civil mediante escritos de diversa índole. De esta manera, la Iglesia no excluía al liberalismo (que en su acepción amplia apunta a la democracia) como origen y forma de gobierno, frente a lo que opinaban amplios sectores de la misma Iglesia.

La presente comunicación plantea cómo se recibieron esos documentos en la sede hispalense y la respuesta que dio desde los sectores tradicionalistas, liberales y republicanos. A través de este análisis conoceremos el grado de aceptación en los sectores confesionales del régimen liberal y, derivado del mismo, la posibilidad de crear organizaciones políticas concretas que fuesen capaces de aglutinar y disputar el terreno electoral a otras opciones políticas, fundamentalmente a las liberales. 


\section{POLITICA Y MAGISTERIO DE LA IGLESIA}

Durante el siglo XIX surgieron en el ámbito del pensamiento católico europeo dos grupos antagónicos que se manifestaban coincidentes en realizar esfuerzos para servir los intereses de la Iglesia pero discrepantes en la forma y manera de su consecución. En el fondo les separaba la distinta concepción de lo que venía a llamarse el "mundo moderno", mundo emanado de los principios triunfantes tras el proceso revolucionario francés. Mientas que para unos significaba el propio siglo, con sus formas de organización y preconizaban una adaptación de la Iglesia a las instituciones liberales, para otros el mismo vocablo significaba la herencia anticristiana de la revolución y, por tanto, era necesario cortar comunicaciones con ese mundo para evitar el error y sus contagios.

Junto a este proceso, la progresiva secularización de la sociedad, en especial durante la segunda mitad del XIX, hacía necesario a los ojos de la Iglesia dar una respuesta a fin de mostrar firmeza y seguridad en el caos. Las ciencias y las revoluciones políticas prescindían cada vez más de la autoridad de la Iglesia. Frente a una religión de amplias libertades, otros creyentes querían confirmar los derechos de Dios sobre la sociedad y los espíritus. De aquí surgieron las tendencias ultramontanas, vistas en general como una renovación espiritual por cuanto venían a constituir un auténtico muro de contención ante la progresiva secularización de la sociedad (1).

Es en este contexto en el que surgieron los documentos de Gregorio XVII y Pío IX. Este último promulgó en 1864 la Quanta Cura, con su anexo, el Syllabus, sin duda y, a juicio de historiadores cualificados, el documento pontificio más citado en los cien años que siguieron a su promulgación, el cual fue tomado como bandera por los ultramontanos en su enfrentamiento con los sectores católicos más abiertos. Es más: estos últimos creyeron que se eliminaba la posibilidad de una democracia en política, una tolerancia de cultos y otras libertades en el seno de la Iglesia católica. Se hace preciso observar como el Syllabus quedó como símbolo de antagonismos encontrados, rechazado por quienes los consideraban detractor de los tiempos modernos e invocado por quienes querían justificar así la vuelta del

(1) En este sentido Marta CAMPOMAR (la cuestión religiosa durante la Restauración, Santander, 1984, p. 28) nos dice como ese ultramontanismo "era una necesidad para sobrevivir a los golpes de una sociedad cada día más materialista, más dada al libre pensamiento emancipador de los protestantes, que ponía en tela de juicio la autoridad de la Iglesia". 
absolutismo, aún cuando el citado documento no condenaba las libertades e incluso con el mismo texto, podía haber sido posible la defensa de las libertades desde otras perspectivas (2).

Fue León XIII quien emprendió la tarea de conciliar la tradición con el espíritu moderno sin menguar el relevante papel de la Iglesia. En medio de una sociedad en continuo cambio político trató de sacar al papado de la actitud negativa en el que le había situado el Syllabus, abriéndose a cuestiones concretas de su tiempo. Con gran habilidad trató de suavizar el enfrentamiento existente contra los partidarios del liberalismo sin desautorizar lo señalado: por sus antecesores. El Syllabus no debía ser aplicado en todo su rigor sino que éste vendría atenuado con una política más oportunista, por una aceptación de los hechos consumados o, lo que es igual, la teoría de la alianza con el mal menor ante el mayor peligro que suponía ya el avance del socialismo dispuesto a acabar con las tesis católicas.

Mediante la encíclica Diuturnum (1881), referida a la necesidad de la autoridad en todas las sociedades, León XIII recordaba que ese principio natural del derecho a mandar derivaba de Dios y, si bien el Estado ideal era la Monarquía, en algunas circunstancias los gobernantes podían ser elegidos por voluntad y deliberación de la multitud, entendiéndose que se elegía a quien ejercía la autoridad pero no a sus derechos u origen. Se daba el primer paso para compatibilizar Estado Liberal e Iglesia, a la vez que se despojaba al sistema político emanado de una elección de su carácter revolucionario (3).

En lo que a nosotros nos interesa ahora, la Cum multa (1882) como documento pontificio tiene un interés político general y a que trascendió de sus iniciales destinatarios -los prelados españoles, utili-

(2) ANDRES GALLEGO, José: Regeneracionismo y política confesional en España", en Archivos Hispalense, n. ${ }^{\circ} 166$ (1971), p. 1.

(3) La doctrina de la Iglesia establecía que el poader sólo podía proceder de Dios, cuestión que entra en cotradicción con los ideales de la revolución que establecenque provenía del pueblo y éste lo cedía a los goberanntes. Según establecía esta encíclica, "de otra manera sienten los católicos, quienes serivan de Dios el derecho de mandar, como de su principio natural y necesario. Importa sin embargo notar aquí que pueden en algunos circunstancias ser elegidos por voluntad y deliberación de las multitudes los gobernantes, sinque esto contrarie o repugne a la doctrina católica". De esta manera, quedaba desechado el principio revolucionario originario: para los católicos el poder venía de Dios siempre, siendo el pueblo con sus elecciones, mero transmisor del msimo. Diutwnum III vol, en Boletín Oficial del Arzobispo de Sevilla (en adelante BOAS), t. XXVIII (1881), p. 420 . Véase además KOHLER, Oscar: "Desarrollo de los catolicismo en la sociedad, Manual de Historia de la Iglesia (H. Jedín, dir.), Barcelona, Herder, 1984, t. VIII, p. 344. 
zados como argumento- para convertirse en la exposición de una de las ideas fundamentales del pontificado de León XIII: lo impropio que resultaba identificar la causa religiosa con un partido político concreto (tesis que sería desarrollada con posterioridad en Graves de communi). A su juicio, las cuestiones políticas eran temporales mientras que las religiosas eran trascendentes (4).

A través de Inmortale Dei (1885) se completaban las anteriores encíclicas al abordar el tema de la participación política de los católicos. Aunque redactada con la mirada puesta en Francia, a fin de evitar el que se consumase la separación entre la Iglesia y el Estado, el documento era bastante explícito en cuanto a lo referido a las relaciones Iglesia-Estado en los siguientes aspectos: cualquier forma de organización del Estado puede ser compatible con la Iglesia; en ocasiones y desde una legislación determinada la intervención de los católicos en la vida pública debía ser necesaria; los gobernantes elegidos no tenían por qué ejecutar obligatoriamente la voluntad popular. En consecuencia, es "por consiguiente, calumnia vacía y sin contenido lo que dicen algunos sobre que la Iglesia mira con malos ojos el régimen moderno de los Estados, rechazando, sin discreción, todo cuanto ha producido el ingenio en estos tiempos" (5). No cabía duda ante tales afirmaciones que, si bien los pasos eran lentos, se avanzaba hacia una nueva concepción de lo que debía entenderse por relaciones Iglesiapoder político.

En 1888 en Libertas se pronunciaba el Sumo Pontífice sobre la naturaleza de la libertad, entendida de distinta manera por católicos y liberales. El pontífice condenaba los derechos humanos liberales a la vez que anteponía el concepto de libertad emanado del magisterio tradicional de la Iglesia. Era una postura aún más conciliadora en la que se exhortaba a la obediencia a la autoridad del Estado prohibiendo el alzamiento por cuenta propia y llegando a afirmar que, en situaciones desesperadas, cabía la posibilidad de la oración y la paciencia; el recurso a la fuerza quedaba restringido hasta cuando se exigiera algo contrario al derecho divino y natural (6). Con posterioridad la Saphientiae Cristianae (1890), acerca de las obligaciones de los cristiano, recogía argumento esgrimidos en anteriores textos pontificios.

(4) GUTIERREZ GARCIA, José Luis: Doctrina Pontificia II. Documentos Politicos. Madrid, BAC, 1958, págs. 127-128.

(5) Inmortale Dei Miserntis, en BOAS, t. IV (1885), págs. 387-461.

(6) Libertas, en $B O A S$, t. X (2. s. 1988), pág. 120 y ss. 


\section{LA IGLESIA SEVILLANA (7)}

Desde 1881 a 1891 la diócesis sevillana conoció un total de tres prelados: Lluch y Garriga, González y Díaz-Tuñón, y Sanz y Forés. El prestigio de una sede como la sevillana, una de las pocas archidiócesis a cuyo frente figuraba un cardenal, hacía que la concesión de esta silla fuese el peldaño final de una larga carrera eclesiástica, influyendo de esta manera en la edad de los candidatos. De otro lado, y como venía siendo tradicional, el gobierno solía "premiar" con estas sedes a prelado que no fuesen opuestos al clima de tolerancia que rezumaba toda la obra de la Restauración una vez superadas las dificultades que envolvieron la proclamación de la Constitución de 1876. Ambas situaciones determinaban largos y frecuentes períodos de sede vacante, por lo que eran personajes de segunda fila los encargados de efectuar los comentarios a los textos pontificios como ocurrió con la totalidad de los reseñados con anterioridad. Unas veces como sede vacante y otras siguiendo instrucciones del prelado que se encontraba ausente, bien el obispo auxiliar o el vicario capitular eran quienes efectuaban los comentarios, generalmente laudatorios, del texto pontificio, instruyendo la difusión del mismo a los clérigos.

Los tres prelados que ocuparon la diócesis en esta década se caracterizaron por la poca simpatía que profesaban hacia ese integrismo o tradicionalismo, a veces visceral, que dominaba amplios sectores de la Iglesia y sociedad sevillana. Esa antipatía llegó a cotas extremas en el caso del cardenal Lluch en el ocaso de su vida, durante 1882. La negativa del prelado a que la organización de la peregrinación a Roma que contaba con la bendición papal corriera a cargo de Nocedal y de elementos carlistas, o su actitud ante el Centenario de Murillo, son muestras de esa postura contraria a la intransigencia. Durante su pontificado no tuvo inconveniente en incluir en el boletín diocesano noticias tomadas de la prensa liberal frente a lo que había sido un coto cerrado al uso de textos provenientes casi en exclusividad, de publicaciones de marcado carácter tradicionalista. No obstante, la actitud de Lluch no debe llevarnos a considerarle un prelado liberal en el sentido que esta palabra tiene en la praxis política. Al contrario: en distintas ocasiones mostró su desacuerdo con disposiciones gubernamentales de los liberales relativas a la educación o al matrimonio, recordando a este respecto las proposiciones del Syllabus.

(7) Consúltese a este respecto RUIZ SANCHEZ, J. L.: Política e Iglesia sevillana durante la Restauración. Los Origenes de la Liga Católica (inédito). Sevilla, Departamento de Historia Contemporánea, 1988, págs. 37-56. 
De fray Zeferino González -quizás la figura más sobresaliente de todo el episcopado español por sus estudios sobre la escolástica- nos quedan testimonios de su amplia tolerancia. Su acción en el terreno de la política quedaba clarificada en su trayectoria: el apoyo a la Unión Católica de Alejandro Pidal (discípulo suyo) cuando ocupaba la sede de Córdoba denotó su pensamiento y talante sobre la participación de los católicos en política. No obstante su acción en la diócesis de Sevilla en este terreno no dejó ninguna huella conocida; quizás el fracaso de la unión de Pidal o el ambiente más distendido de la confrontación entre los católicos le hizo no actuar abiertamente.

Con respecto a Sanz y Forés, llegado a la diócesis en una fecha algo tardía para nuestro estudio -1890- algunos de los discursos del Congreso Católico Nacional de 1892 encargados por él mismo, o la peregrinación obrera a Roma de 1894, fueron ilustrativos respecto hacia donde debían encaminarse los católicos para conseguir su unidad. La carta pastoral para esta concentración obrera señalaba cómo para atajar la difusión de las ideas disolventes, más que lamentarse o luchar contra los gobiernos, "que al fin suelen ser engendro del voluntario sufragio", lo que había de hacerse era abandonar la apatía y desplegar una mayor actividad.

Junto a esta actitud positiva de los prelados hispalenses en cuanto a lo que era el poder civil y la participación en política a través del sufragio se encontraban los mandos intermedios de la diócesis, en particular el obispo auxiliar de Lluch -Spínola- y el vicario capitular -Mauri o Bermúdez de Cañas-. Este último, al comentar Libertas en el boletín insistía en las prudentes observaciones referidas al tema de la libertad, y cómo León XIII, introduciéndose en la "única situación que las actuales circunstancias colocan a la autoridad pública en los paises católicos", reconocía la necesidad de usar cierta tolerancia, regulada por la prudencia política "sin que esto suponga una aprobación táctica de aquellas". Frente a esta actitud, ciertamente tolerante, la respuesta del resto de la Iglesia diocesana reflejaba una actitud en consonancia con las tesis más ultramontanas y, en gran medida, contrarias a la participación en un sistema que creían iba en total desacuerdo con los postulados pontificios anteriores.

\section{PRENSA SEVILLANA Y DOCUMENTOS PONTIFICIOS}

La actitud de la prensa liberal sevillana ante los documentos pontificios fue, en general complaciente. En la mayoría de los casos, sus páginas sirvieron para efectuar amplia propaganda de los documentos en función del interés de los mismos, no limitándose en exclusividad a reproducir el texto sino efectuando amplios comentarios sobre el contenido de los mismos y su repercusión en la realidad inmediata. De 
toda la prensa sevillana destaca "La Andalucía" -liberal- por espacio y comentarios dedicados a este tema, es especial a la Cum multa.

En efecto fue este documento pontificio el que más rios de tinta hizo correr dada la trascendencia que para unionistas y nocedalinos tenía la carta-encíclica. "La Andalucía" atribuía gran importancia a su contenido pero esperaban de la sabiduría y prudencia del pontífice un comunicado que sirviese para acabar con la lucha que afligía "a los que no mezclan los sentimientos de la religión con los intereses políticos". De igual manera el diario se hacía eco de las esperanzas que abrigaban los partidarios de la Unión Católica si bien creía "La Andalucía" que para superar las dificultades era un obstáculo la Compañía de Jesús, "dominadora hoy de la corte de Roma a pesar de las resistencias del Sumo Pontífice", y el apoyo firme que venía sustentando "El Siglo Futuro", órgano del tradicionalismo (8).

Aunque el sentido de la encíclica era ése, el apoyo a las tesis unionistas y la llamada a la atención de los seguidores de Nocedal, los acontecimientos discurrieron por derroteros muy distintos a los que los primeros esperaban. La prensa liberal sevillana conoció el contenido del documento a través de la información sesgada que facilitó "El Siglo Futuro"; los comentarios del diario de Nocedal, que adelantaba un contenido favorable a sus postulados adjudicándose por tanto un triunfo sobre unionistas, llevó a "La Andalucía" a preguntarse por las razones que habian podido influir en "el conciliador y tolerante espíritu de León XIII lpara quel se torne propicio a la política intransigente y demoledora de Nocedal y sus secuaces". A falta de mayor conocimiento de estas razones, reproducía la carta publicada por "El Liberal" de Madrid en la que se culpaba a los jesuitas de esta supuesta actitud del Papa. No obstante y por si acaso se hubiese mal interpretado el pensamiento de Roma (no olvidemos que sólo se conocía el documento por las informaciones de "El Siglo Futuro") el diario liberal aplazaba sus comentarios a la espera de conocer la integridad del documento. De lo que sí se hizo eco fue de la visión que tenían los unionistas. Para éstos no se tenía certeza ni tan siquiera de haberse concluido la encíclica, considerando que la carta a través de la cual había sido conocido era pura falsedad al no ser posible que "un pontífice tan ilustrado como León XIII asiente ni autorice las exageraciones del Obispo de Daulia ni los dislates del Siglo Futuro (sic), cuando todo ello está en contradicción con actos y prescripciones anteriores del Pontífice" (9).

(8) "La Andalucía" de Sevilla, 19 y 20 de diciembre de 1882.

(9) "El Porvenir" de Sevilla, 22 de diciembre de 1882. "La Andalucía" de 23 de diciembre de 1882 . 
A pesar de todo, la opinión de "La Andalucía" respecto a la actuación del Vaticano, no sólo en esto sino en cuestiones similares, era clara: Roma no se indispondría con unos ni con otros, porque a todos necesitaba para conservar su fuerza; por tanto, procuraría mantener el equilibrio adoptando su tradicional política de habilidades por lo cual, "cuando no puede pasar por otro punto, invoca la conveniencia de los intereses religiosos para amoldarse, siquiera sea aparentemente, a lo que de ello exigen las volubles circunstancias de los tiempos". Ahí radicaba -a juicio de "La Andalucía"- el secreto del Vaticano: en resistir siempre que vea, aunque lejana, la seguridad de triunfo; y cuando observe que existe un divorcio entre ella y la sociedad civil, procura adaptarse a las transformaciones de los tiempos, cediendo en lo secundario y tratando de salvar lo fundamental que por potestad divina tiene conferido. En esta actitud ambivalente encontrarían, tanto unionistas como nocedalinos, los argumentos necesarios para seguir defendiendo sus posiciones.

Al conocerse el texto pontificio "La Andalucía", aunque no lo insertó por falta -según dijo- de espacio, extractó los rasgos más sobresalientes: el llamamiento a los cristianos para unirse, insistiendo que la Iglesia no condenaba las parcialidades políticas siempre que no riñeran con la religión y la justicia; la defensa de la autoridad del prelado; la no beligerancia de los sacerdotes en la lucha de los partidos. A juicio del diario sevillano, la encíclica había sido escrita para acabar con el principio de cisma que los carlistas habían iniciado al querer erigirse en defensores únicos del catolicismo ortodoxo frente a los unionistas. Para el diario, si algo resultaba anatemizado en el documento papal era "el espíritu de intolerancia y de injusticia que informa toda la política de El Siglo Futuro". Por ello mantenía firmes sus censuras respecto a la actitud de los carlistas:

"De modo que quiere el Inmortal León XIII que no se tome a la religión como instrumento de engrandecimiento de ningún partido; y debiendo el carlismo darse por aludido el primero, por ser el único que utiliza la religión como recurso, afirmando que no es ni puede ser católico el que no sea carlista, sin embargo, es el que con osadía y para consagrar la causa carlista, como la única legítima y conforme con la doctrina eclesiástica" (10).

Y dado que los seguidores de Nocedal no se daban por aludidos con el documento, éste tendría nula consecuencia; al contrario, serviría para abrir más el abismo que separaba a los carlistas de las restantes organizaciones políticas.

(10) "La Andalucía" de 23, 24 y 27 de diciembre de 1882. 
Por su parte, la prensa tradicionalista sevillana consultada recibió el texto ensalzándolo e insistiendo -como lo había hecho a nivel nacional- en que "ni un sólo paso hemos dado sin la censura de nuestros Pastores", lo que constituía afirmar que la encíclica no estaba causada por ellos, cuando todo indicaba lo contrario (11).

La promulgación de Inmortale sirvió de nuevo para que la prensa liberal sevillana insistiese en el espíritu de tolerancia de León XIII. "El Español" -canovista, publicó integramente el documento- afirmó que las enseñanzas de la Santa Sede no se discutían, sencillamente se obedecían, comentario que aludía a la actitud de los carlistas. El diario se mostraba seguro de que si el papa viviese muchos años desaparecerían todas las disidencias y antagonismos existentes en la Iglesia consecuencia de los "severos temperamentos adoptados en no lejanos tiempos para constreñir los progresos de la herejía". La encíclica era una prueba de que en el ánimo de León XIII "no predominan las intransigencias ni los exclusivismos" y de que en política la postura pontificia se inclinaba por una amplia libertad y expansión "para todo lo que no sea [ir] en contra de los fundamentos, de las herencias, de las afirmaciones de la Iglesia católica" (12).

Ese mismo espíritu de tolerancia y el ver con buenos ojos la participación de los católicos en la constitución de la sociedad humana eran, igualmente, las características que destacaba "El Progreso" y "La Andalucía", diarios que reprodujeron pasajes íntegros del documento. Junto a esas características destacaban el que se mencionase que el poder para gobernar no tenía que seguir la opinión de la multitud sino encaminarse a la verdad y a la justicia. Aunque este documento pontificio, como los anteriores, debía haber incluido notablemente de cara a unir a los católicos españoles, sin embargo, no produjo efectos inmediatos notables (13).

En cuanto a Libertas (14), publicaron el documento "La Andalucía" y "El Español"; pero fué el republicano "El Baluarte" quien comentó más detenidamente la encíclica a la que considera "muy templada y tolerante, como no podía menos de suceder, dado el temperamento conciliador que hoy parece dominar en el Vaticano". Para este diario, el documento papal estaba bastante relacionado con la situa-

(11) "La Revista Católica" de Sevilla, t. V (1882), p. 832.

(12) "El Español" de Sevilla, 17 de noviembre de 1885.

(13) "El Progreso" de 13 y 17 de noviembre de 1885. "La Andalucía" de 15 y 17 de noviembre de 1885 .

(14) Se han consultado los meses de junio, julio y agosto de 1888 de "La Andalucía" y "El Tributo", y los de julio y agosto de "El Español", "El Progreso" y "El Baluarte". 
ción italiana, donde unos aconsejaban el absentismo de los católicos, otros pedían la participación en las elecciones al parlamento y otros sugerían que León XIII abandonase Italia. No obstante, era en el carácter tolerante del documento en donde más se insistía; incluso llegó a afirmar que podía ser considerado el texto una derogación del Syllabus y que la obra de Pío IX había fracasado por completo. Y es que para este diario republicano, la relativa tolerancia de las libertades -allí en donde se hallaban establecidas y respondían a un carácter nacional- daban a entender que las mismas "no constituían pecado". Aún así, no desbordaban su confianza en el papa Pecci:

"Mal haria, no obstante, el espíritu liberal confiar demasiado en estas predicaciones de tardía tolerancia. La Encíclica lo declara: las libertades moderadas son toleradas por la Iglesia como un mal necesario, inherente a la imperfección humana, y sólo con el propósito de evitar mayores daños. La tolerancia, que es una virtud para el siglo, no es para la Iglesia sino un signo de debilidad. No son la verdad y el bien, sino el mal y el error que se tolera, decía el ilustre Balmes, pretendiendo explicar el sentido de la palabra tolerancia" (15).

Para "El Baluarte" el documento no tenía otro objeto que el intento de acabar con el divorcio existente entre la Iglesia y la sociedad para lo cual el Sumo Pontífice transigía en ofrecer determinadas concesiones parciales. El texto de "relativa transigencia" habría de molestar a los íntegros, "sinceros y fervientes sectarios de las tradiciones de intolerancia del anterior pontificado", pero no por ello convencería a la opinión dominante en Europa.

\section{ANTE LA APLICACION DE LA LEY DE SUFRAGIO UNIVERSAL}

Una vez aprobada la ley que regulaba el sufragio universal en España las primeras elecciones celebradas bajo su normativa fueron las provinciales en diciembre de 1890. La prensa liberal de todos los matices reconocía el gran paso que significaba para el país en el camino del progreso dicha ley, a la vez que reconocía que se tardarian algunos años en obtener unos resultados correctos. Pero de nada serviría que los españoles mayores de edad tuviesen derecho a participar en los comicios si el descrédito en que habían caído las elecciones no llevaba al colegio electoral más que al elemento oficial y alguna que otra persona ligada a los candidatos por vínculo de parentesco o ideales políticos. Tan sólo -a juicio de "La Andalucía"- se llegaría a ese día deseado en que las corporaciones populares y gobiernos sean antes

(15) "El Baluarte" de Sevilla de 3 de junio de 1888 
centros administrativos que políticos, que antepongan el interés de la nación al particular, cuando el pueblo se de cuenta de que al ejercer el sufragio se realiza un deber sagrado. Pero creía que eso aún no era posible en España por cuanto el elemento oficial tenía de antemano ganadas las mesas, colocando como presidentes de las mismas a sus correligionarios, además de contar con las ventajas que le proporcionaba el ocupar el gobierno, el haberse preparado a tiempo y el haber nombrado las corporaciones populares a su antojo quitando y trasladando empleos y procurando por todos los medios a su alcance el conseguir la victoria electoral (16).

Tras las elecciones provinciales la desilusión fue tremenda. La práctica totalidad de la prensa liberal ("La Andalucía", "El Progreso", "El Baluarte", "El Cronista", etc.) coincidían en la farsa electoral. Y es que, si bien la ley restablecía el procedimiento que garantizaba la exactitud del resultado reflejado en las urnas, en Sevilla no se había respetado el escrutinio público, pudiéndose en consecuencia repetirse los vicios anteriores. Eso hacía exclamar al primero de los diarios citados como "el parlamentarismo es un cáncer que corroe la patria, porque él mismo sostiene el caciquismo en los pueblos y excusa de las inmoralidades administrativas de todo género, consumiéndose así las fuerzas para la prosperidad de la patria" (17). El primer ensayo de la ley en la que se habían puesto tantas esperanzas constituyó un auténtico fracaso pero, lejos de seguir creyendo en la misma y en su progresiva implantación, parecía quebrantarse las esperanzas de que se estaba en el camino de la regeneración política tan ansiada.

Por su parte, la prensa católica ante esa realidad tangible que significaba el nuevo sufragio no hacía sino recordar lo que semanas antes habían acordado en Zaragoza los prelados españoles reunidos con motivo de la celebración del congreso católico nacional. Las cláusulas establecidas por los mismos incidía en el magisterio de León XIII sobre la participación en política además de obligar a los católicos -fundamentalmente a los tradicionalistas, carlistas o integristas- a no calificar de liberales a los que tomasen parte en las elecciones para la gestión de los negocios públicos. $\mathrm{Y}$ ante las primeras elecciones a Cortes con la nueva ley, aparte de recomendar lo establecido en Zarago$\mathrm{za}$, recordaban circulares de distintos prelados sobre el particular, en concreto la del obispo de Plasencia, una de las más restrictivas (18).

(16) "La Andalucía" de 28 de noviembre de 1890.

(17) Cfr. "La Andalucía" de 10 de diciembre de 1990.

(18) "La Revista Cátólica", t. XIII (1890), págs. 740-742; t. XIV (1891), págs. 49-51. 


\section{CONCLUSIONES}

5.1. Durante el pontificado de León XIII se hace el mayor esfuerzo por adaptar el pensamiento sobre política de la Iglesia a las nuevas realidades surgidas tras el triunfo de los ideales revolucionarios. Esa adaptación no supone una renuncia a principios fundamentales defendidos por la Iglesia sino una cesión en los aspectos accesorios, secundarios, y en una aceptación del mal menor frente a otras ideas emergentes que eran -a juicio de la Iglesia- más disolventes para la sociedad.

5.2. El objetivo final de los textos pontificios quedaba claro: aceptación de la autoridad constituída emanada de un proceso voluntario del individuo, el sufragio, no considerada perjudicial la forma en que es determinada la autoridad; acabar con el uso partidista que de la Iglesia efectuaban determinadas organizaciones políticas concretas; la necesidad de participar en el juego político y acatar el resultado de unas elecciones salvo circunstancias muy especiales. De esta manera, los católicos debían no sólo aceptar sino participar en el sufragio.

5.3. En España los documentos pontificios tuvieron especial resonancia por cuanto recaían sobre una población mayoritariamente católica con independencia del credo político tradicionalista o liberal. A pesar de la obcecación de los sectores más recalcitrantes que interpretaban el Syllabus de una manera restrictiva al máximo, lo cierto era que los textos pontificios no les eran favorables. Por esta razón la prensa liberal en general y la sevillana en particular, al hacerse eco de las palabras del Papa, dedicaban abundante espacio a comentar cual sería la actitud de los tradicionalistas al conocer el pensamiento de León XIII.

5.4. En una estructura jeraquizada como es la Iglesia, la recepción de cualquier encíclica implicaba una total asunción de lo enunciado. Los comentarios a los textos pontificios realizados desde la silla hispalense fueron, simplemente, laudatorios. Nada tiene de extraño que llevasen la firma de un miembro de segunda fila de la jerarquía eclesiástica dadas las características de una diócesis de esta categoría, en la que abundaban los períodos de sede vacante o ausencia del prelado por enfermedad.

5.5. La prensa liberal sevillana se hizo eco de los documentos pontificios recibiéndolos con beneplácito y sin sorpresa la provenir de León XIII, pontífice de declarado espíritu tolerante en contraste con sus antecesores. de toda la prensa liberal sevillana fue "La Andalucía" y "El Español" quiénes más tinta hicieron correr con motivo de la promulgación de las encíclicas. La prensa católica consultada se muestra en este sentido laudatoria. 
5.6. La Cum multa fue la encíclica que más comentarios prodigó. Las razones hay que situarlas en el destino específico que la misma tenía (el sometimiento a los prelados de cualquier actuación política de los católicos y la llamada de atención a los sectores tradicionalistas frente a su actitud contra los unionistas) y la situación derivada de los sucesos producidos en la ciudad meses antes de la aparición de la encíclica con motivo de la celebración del Centenario de Murillo.

5.7. No se produjeron resultados inmediatos de adaptación de los católicos más recalcitrantes al sistema liberal. Aunque la jerarquía eclesiástica era ciertamente tolerante, el resto del clero y fieles mostraba un marcado cariz tradicionalista y por ello era imposible crear un frente católico común, diverso en planteamientos, de acuerdo en cuanto a la defensa de los intereses de la Iglesia. No obstante una vez aprobada la ley del sufragio universal y con la existencia de la nueva doctrina de la Iglesia en cuanto a la participación de los católicos en política, quedaban sentadas las bases para establecer organizaciones políticas confesionales capaces de medir sus fuerzas en una consulta electoral.

5.8. Para la fecha de la aprobación de la nueva ley de sufragio electoral, aparte de contar con el magisterio de la Iglesia desde Roma, se contaba con los documentos concretos elaborados por los prelados españoles conjuntamente en las sesiones de los congresos católicos celebrados hasta ese momento y que abordaban temas concretos de la realidad española. 